\title{
MUON PHASE ROTATION USING AN INDUCTION LINAC*
}

\author{
L. Reginato, S. Yu, M. Green and D. Vanecek \\ Lawrence Berkeley National Laboratory, Berkeley, CA. 94720 USA
}

\begin{abstract}
The proposed neutrino factory requires that the muons produced by the decay of pions and kaons produced by a target be phase-rotated before they can be cooled and then accelerated. This report describes a muon phaserotation system that employs an induction acceleration system. The phase-rotation system consists of a 100meter long induction accelerator, a mini-cooling system with magnetic flux reversal, and two 80-meter long induction linacs with a drift space between them. The induction linac phase-rotation system uses a $620-\mathrm{mm}$ warm bore $1.25 \mathrm{~T}$ superconducting solenoid to guide the muons in the beam channel. The phase-rotation linac is divided into 1-meter long components each with its superconducting solenoid. This report describes the induction cells, the induction cell power system, and the superconducting solenoid contained within those cells.
\end{abstract}

\section{INTRODUCTION}

The principle of magnetic induction has been applied to the acceleration of high current beams in betatrons and a variety of induction accelerators. ${ }^{1}$ The linear induction accelerator (LIA) consists of a simple nonresonant structure where the drive voltage is applied to an axially symmetric gap that encloses a toroidal ferromagnetic material. The LIA is typically a low gradient structure that can provide acceleration fields of varying shapes and time durations from tens of nanoseconds to several microseconds. The acceleration voltage available is simply given by the expression $\mathrm{V}=\mathrm{A} \mathrm{dB} / \mathrm{dt}$. Hence, for a given cross section of material, the beam pulse duration influences the energy gain. Furthermore, a premium is put on minimizing the diameter, which impacts the total weight or cost of the magnetic material. The diameter doubly impacts the cost of the LIA since the power (cost) to drive the cores is proportional to the volume as well.

The waveform requirements during the beam pulse makes it necessary to make provisions in the pulsing system to maintain the desired $\mathrm{dB} / \mathrm{dt}$ during the useful part of the acceleration cycle. This is typically done two ways, by using the final stage of the pulse forming network (PFN) and by the pulse compensation network usually in close proximity of the acceleration cell.

The choice of magnetic materials will be made by testing various materials both ferromagnetic and ferrimagnetic. These materials will include the nickel-iron, silicon steel amorphous and various types of ferrites not only to determine the properties that are essential in this application but the energy losses in the magnetization process which directly impact the cost.

\section{INDUCTION ACCELERATORS DESIGN}

The parameter and pulse format selected under Study 2 offered improved physics performance and less demanding induction accelerator waveforms. The Feasibility Study 2 of the Neutrino Factory and Muon Collider have resulted in the architecture shown on Fig. 1 and the acceleration waveforms shown on Fig. 2. The waveforms of the three induction accelerators are unipolar, that is they do not reverse in polarity during the beam pulse. Induction 1 and 3 are providing acceleration cycles of about $200 \mathrm{~ns}$ and 400 ns respectively while Induction 2 is decelerating and

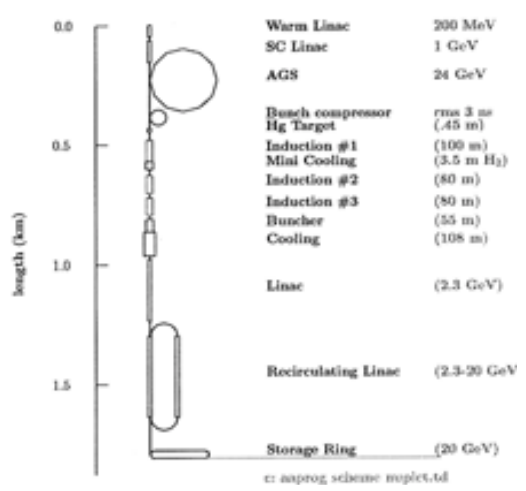

Fig. 1 Neutrino Factory and Muon Collider

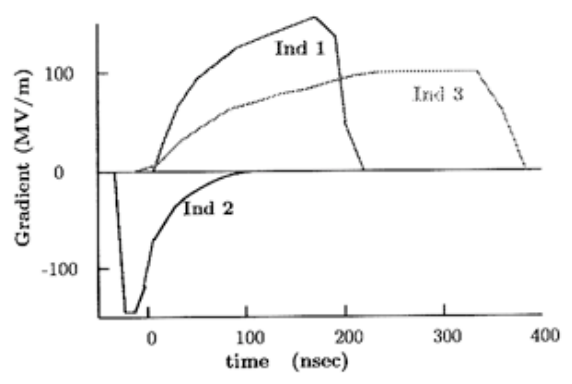

Fig. 2 Acceleration Waveforms

has a duration of about $50 \mathrm{~ns}$. A number of induction accelerators have been constructed in the past that cover the pulse duration required by the Neutrino Factory and Muon Collider but none that have acceleration gradients and peak power levels that are as high. Concentrically located inside of the induction cells thus requiring a very large inside diameters (Fig.3). Furthermore, the stray solenoidal fields at the gaps require an even larger diameter to insure that these fields orthogonal to the main field do not cause a reduction in total flux available. The high gradient and solenoids dictate an induction cell design which is far from optimum in terms of power requirements and economics. 
In the past two decades, great strides have been made in the development of magnetic materials which are replacing all previous ones used $\mathrm{n}$ the $60 \mathrm{~Hz}$ power industry because of low loss, ease of manufacturing and low cost. These materials are amorphous alloys which are manufactured in ribbon form by rapidly quenching a stream of molten materials on a cold rotating drum. The ribbon is cast in thicknesses of 15-25 $\mathrm{m}$ and has a greater resistivity than other magnetic materials making it directly applicable for short pulse applications. In previous induction accelerators where the pulse duration was velow $100 \mathrm{~ns}$, it has been traditional to use ferrites as the magnetic material. Ferrites were chosen simply because they offered the lowest energy loss and minimum overall cost. For Induction 2 with a $50 \mathrm{~ns}$ pulse duration ferrites were the obvious choice. However, further cost analysis indicated that even though the energy loss was less for ferrites, overall cost benefits resulted from using amorphous materials. This shift in cost benefit has occurred because the cost of manufacturing ferrites has been increasing while the cost of amorphous alloys has been decreasing offsetting the increase in the cost of driving the induction cells. In order to make a good comparison, a thorough design was made using the two materials and their respective drive modulators. If full saturation is achieved in $50 \mathrm{~ns}$, the losses for ferrites (CMD 5005) are about $800 \mathrm{~J} / \mathrm{m}^{3}$ while the losses for amorphous materials (2605SC) are more than one order of magnitude higher. Since the cost of ferrites has increased considerably in the past two decades while the cost of amorphous materials has decreased, it was imperative to take another look at using amorphous materials of the same cross-section (volume) as the ferrites since this would mean that the flux swing would be much lower than that at full saturation as would be the magnetization rates, hence, the losses. In order to make the best comparison, a design was made of both the ferrites and the amorphous materials. Using the standard $101.6 \mathrm{~mm}$ width $(\mathrm{w})$ and a delta $\mathrm{B}$ of 0.5 Tesla for the ferrite CMD 5005 then the area $A=w\left(r_{2}-r_{1}\right)=V$ t/ $B$. From Fig. 2 the significant part of the acceleration waveform is the fall time while the rise time is unspecified and will be determined by the pulse generators. Because of the large gap capacitance and the impedance of the pulse generator, the rise time will be nearly the same as the fall time so that the FWHM will be about $100 \mathrm{~ns}$.

Using $100 \mathrm{~ns}$ as FWHM or $\mathrm{t}$ and the per cell voltage $\mathrm{V}=188 \mathrm{kV}$ then the outside radius $\mathrm{r}_{2}=870 \mathrm{~mm}$. The hystesisis curve for CMD 5005 indicates that $\mathrm{H}=1000 \mathrm{~A} / \mathrm{m}$ and the losses will be $500 \mathrm{~J} / \mathrm{m}^{3}$. The ferrite volume $\mathrm{V}=\left(\mathrm{r}_{2}^{2}-\mathrm{r}_{1}^{2}\right) \mathrm{W}=.162 \mathrm{~m}^{3}$ which will result in $81 \mathrm{~J}$ of losses per cell requiring a drive current $\mathrm{I}=4.3 \mathrm{kA}$. Using the same cross sectional area but applying the amorphous materials, one can now find the losses. Because the packing factor of the amorphous material will be 0.75 instead of unity the flux swing will be $.667 \mathrm{~T}$ and the magnetization rate $\mathrm{dB} / \mathrm{dt}=6.67 \mathrm{~T} / \mathrm{s}$ (i.e $100 \mathrm{~ns}$ saturation). The losses for $2605 \mathrm{SC}$ will be about 1400 $\mathrm{J} / \mathrm{m}^{3}$. The total losses, $\mathrm{U}$, for the amorphous material will be $\mathrm{U}=\left(1400 \mathrm{~J} / \mathrm{m}^{3}\right)\left(.162 \mathrm{~m}^{3}\right)(.75)$ or $\mathrm{U}=170 \mathrm{~J} /$ cell. The losses using the amorphous material are about twice as high as those of the ferrites and, therefore, the cost of the pulse generator will be greater. The economics, however, still favor the amorphous material because its cost is about one fourth of that of the ferrites. Even though the pulse generator nearly doubles in cost, the net result is a saving of about $10 \%$. An additional advantage is that all three accelerators are almost identical in design. The design of Induction 1, 2 and 3 is shown on Table 1.

TABLE 1
\begin{tabular}{|l|c|c|c|c|c|c|}
\hline Accel & $\begin{array}{r}\mathbf{t} \\
\mathbf{n ~ s}\end{array}$ & $\begin{array}{c}\mathbf{B} \\
\text { Tesla }\end{array}$ & $\begin{array}{c}\mathbf{H} \\
\mathbf{A} / \mathbf{m}\end{array}$ & $\begin{array}{c}\text { Volts } \\
\text { KV }\end{array}$ & $\begin{array}{c}\text { Amps } \\
\text { KA }\end{array}$ & $\begin{array}{c}\text { Energy } \\
\mathbf{J}\end{array}$ \\
\hline Ind 1 & 250 & 2.0 & 1200 & 214 & 5.09 & 273 \\
\hline Ind 2 & 100 & 0.67 & 2100 & 188 & 9.05 & 170 \\
\hline Ind 3 & 380 & 2.0 & 900 & 143 & 3.84 & 209 \\
\hline
\end{tabular}

\section{PULSE GENERATORS}

Induction Accelreators 1, 2 and 3 are driven by pulse generators with output voltages of several hundred kilovolts and currents in the tens of kiloamperes. Prior to

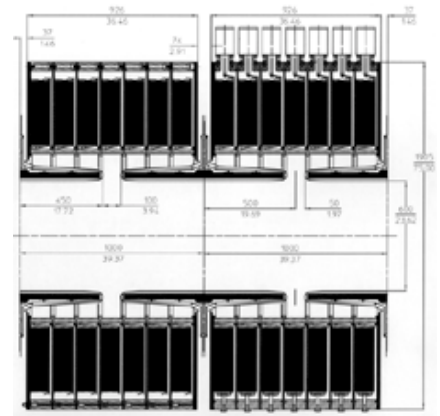
the development of the nonlinear magnetic pulse compression modulator, it has been traditional to drive the induction cells directly from line modulators. Because of the very high voltages and currents required by the induction

Fig. 3-Typical cross-section of two meters

linacs, the only modulator that can provide short pulses with such high peak power levels (several gigawatts) is the magnetic pulse compression type.

The requirement for induction 1 is to generate an acceleration pulse shape and gradient shown on Fig 1 and 2. Each accelerator cell previously described must produce a voltage of $214 \mathrm{kV}$ and after the beam traverses 700 of these cells it will have gained $150 \mathrm{MV}$ of energy. From Table I, the necessary drive current for one cell is $5.09 \mathrm{KA}$ for a duration full width half maximum (FWHM) of 250 ns. As previously mentioned, no switches exist which can produce this type of pulse directly so by investigating the optimum operating voltage and current of the switches, the required stages of compression will be decided. Since Thyristors have limits in di/dt of several kiloamperes/microsecond and voltage limits of a few kilovolts it can be seen that a large number of them in series and parallel combination will be required. Thyratrons also have limits in di/dt and voltage but these limits are at least one order of magnitude greater than 
thyristors. Thyristors have practically unlimited life while the thyratrons have an operating life of the order of 20,000 hours. Even taking into consideration replacement costs, the thyratrons offer a simpler and more economical pulse compression system (fewer stages).

For technical and economic reasons, the pulse compression system is designed to drive one meter or all seven induction cells. The total energy required will be $\mathrm{U}=273 \times 7=1,911$ Joules plus the additional losses incurred in the pulse compression scheme. The 500 Joule magnetic pulse compression system designed to replace the Advanced Test Accelerator spark gaps achieved an efficiency approaching $90 \%$. Allowing for 5\% losses in the thyratron switches, $5 \%$ losses in the resonant charging and $5 \%$ in the power supply, the total input energy per pulse is 2,548 Joules and at $15 \mathrm{~Hz}$ average repetition rate the total power for seven cells $\mathrm{W}=38.2 \mathrm{~kW}$. The total power for Induction $1, \mathrm{~W}_{\mathrm{t}}=3.82 \mathrm{MW}$.

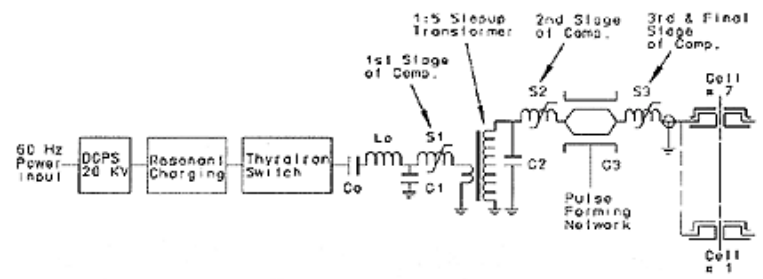

Fig.4-Simplified diagram of a magnetic pulse compression modulator for driving seven cells.

Fig 4 shows a simplified diagrams of the pulse generator which will drive 7 cells with a voltage pulse of $214 \mathrm{kV}, 35.6 \mathrm{kA}$ and a pulse duration FWHM=250ns. The resonant charger initiates the sequence by charging capacitor $\mathrm{C}_{0}$ to $2 \mathrm{xVdcps}$ or $30-40 \mathrm{kV}$. The charging current through $\mathrm{C}_{0}$ will have the effect of partially resetting the first stage compression and the step up transformer. The reset of the other stages and the induction cells will be done by a separate pulse generator just prior to initiating the pulse sequence. The pulse compression sequence is initiated by firing the switches and discharging $\mathrm{C}_{0}$ into the first stage of compression. After two more stages of pulse compression and pulse shaping, the waveform is delivered to seven induction cells. The total energy that must be switchd by the thyratrons include the system losses and amounts to 2548 Joules. This energy is stored in capacitor $\mathrm{Co}=5.66 \mathrm{~F}$ and is switched into $\mathrm{C} 1$ through inductor $\mathrm{L} 1=.828 \mathrm{H}$ with a series impedance $\mathrm{Z}_{0}=.382$ ohms.

This results in a peak half sine wave current of $28 \mathrm{kA}$ for a peak power of $2.3 \mathrm{GW}$. Several options in thyratrons are available. This highest continuous power thyratrons are the ceramic envelope units while the glass envelope units are capable of nearly as high a peak power with low average power capability. Since the average power is moderate $(38 \mathrm{~kW})$ the appropriate choice for technical and economic reasons are the glass envelope units. In order to carry the $78 \mathrm{kA}$ peak current, twelve parallel devices will have to be used. To insure current sharing, each thryratron will switch its own capacitor which is $\mathrm{Co} / 12=.47 \mathrm{~F}$.

The magnetic pulse compression modulators for Induction 2 and 3 will be very similar to Induction 1 with small variations in the number of stages in accordance with their respective pulse duration.

The total energy per pulse and the total power requirements at $15 \mathrm{~Hz}$ average repetition rate for all three induction accelerators is sown on Table II.

\begin{tabular}{|c|c|c|c|c|}
\hline \multicolumn{5}{|c|}{$\begin{array}{l}\text { TABLE II Energy and Power } \\
\text { Requirements }\end{array}$} \\
\hline Ind. Accel & $\begin{array}{l}\text { Length } \\
\text { (m) }\end{array}$ & $\begin{array}{c}\text { Pulser } \\
\text { Energy } \\
(\mathrm{J} / \mathrm{m})\end{array}$ & $\begin{array}{c}\text { Total } \\
\text { Energy } \\
(\mathrm{kJ})\end{array}$ & $\begin{array}{c}\text { Total } \\
\text { Power } \\
@ \\
15 \mathrm{~Hz} \\
(\mathrm{~kW})\end{array}$ \\
\hline Induction 1 & 100 & 2,548 & 254.8 & 4,247 \\
\hline Induction 2 & 80 & 1,190 & 126.9 & 2,115 \\
\hline Induction 3 & 80 & 1951 & 156.1 & 2,602 \\
\hline \multicolumn{4}{|c|}{ Total Power required from Grid } & $8,964 \mathrm{~kW}$ \\
\hline
\end{tabular}

\section{CONCLUSION}

The proposed neutrino factory phase rotator requires some very demanding pulse shapes and power levels for driving the three induction accelerators. However, a number of induction accelerators and magnetic pulse compression modulators have been constructed which cover the range of pulse duration and peak power levels required. Further studies will be required in the optimization of the magnetic materials and modulator design. There are indications from the manufacturers of the amorphous alloys that a thinner ribbon can be made in mass production thus reducing the overall power requirements. It is quite realistic to expect reductions of $10-20 \%$ in overall power requirements and modulator cost using thinner alloys of the material used for study 2 . Further studies will include the generation of a bipolar pulse using branched magnetic which would result into combining Induction 2 and 3.

\section{REFERENCES}

[1] N.C. Christofilos "High Current Linear Induction Accelerators for Electrons" The Review of Scientific Instruments. Vol. 35, No. 7-July 1964.

[2] W.S Melville "The Use of Saturable Reactors as discharge Devices for Pulse Generators" the Institution of Electrical Engineers. Vol. 98, Part III, No. 53. May 1951

[3] D.L. Birx “ An Investigation Into the Repetition Rate Limitations of Magnetic Switches" UCRL 87278, Feb. 10, 1982, Lawrence Livermore National Laboratory 